\title{
Diversidade genética de acessos de feijão comum por caracteres agronômicos ${ }^{1}$
}

\author{
Genetic diversity of common bean accessions by agronomic traits
}

\author{
Pablo Diego Silva Cabral ${ }^{2 *}$, Taís Cristina Bastos Soares ${ }^{3}$, Andreia Barcelos de Passos Lima ${ }^{4}$, Diogo de Souza \\ Alves $^{5}$ e José Arcanjo Nunes ${ }^{6}$
}

\begin{abstract}
Resumo - Este experimento teve como objetivo avaliar a divergência genética entre 57 acessos de feijão comum, sendo 31 genótipos locais do sul do Espírito Santo, 20 da EMBRAPA e seis cultivares comerciais. Foram realizados três experimentos no município de Alegre, ES nos anos agrícolas de 2008/2009 e de 2009/2010. O delineamento utilizado foi o de blocos casualizados com três repetições. Os dados foram submetidos à análise de variância pelo teste F. Foi utilizada análise multivariada para avaliar a divergência genética entre os acessos utilizando o método de agrupamento UPGMA e variáveis canônicas com base na distância generalizada de Mahalanobis. As variáveis que mais contribuíram para a separação dos acessos foram: peso de cem sementes (P100) com 24,01\%, período vegetativo (PV) com 20,39\%, período reprodutivo (PR) com 17,16\% e comprimento da semente (CS) com 14,87\%. Os acessos menos divergentes foram o F15 e o F18 $(9,18)$ e os mais divergentes foram F10 e F08 $(1308,62)$. Verificou-se baixa dissimilaridade genética entre as cultivares comerciais e também entre os acessos provenientes da EMBRAPA e entre ambas. Os acessos locais demonstraram uma diversidade genética significativa. Tanto a análise de agrupamento quanto a de variáveis canônicas foram capazes de separar os acessos de acordo com os centros de origem.
\end{abstract}

Palavras-chave - Phaseolus vulgaris L.. Caracterização de germoplasma. UPGMA. Variáveis canônicas.

\begin{abstract}
This research aimed to evaluate the genetic divergence among 57 accessions of common bean genotypes being 31 genotypes from southern Espírito Santo, Brazil, 20 cultivars from EMBRAPA and 6 commercial cultivars. Three experiments were conducted in the agricultural years 2008/2009 and 2009/2010, two in the experimental area and a CCA-UFES at IFES, both sites in the municipality of Alegre, ES, Brazil. The desing was a randomized block with tree replications. Data were subjected to analysis of variance test by F. By multivariate analysis assessed the genetic diversity among accessions using the UPGMA clustering method and canonical variables based on the Mahalanobis distance. The variables that contributed most to the separation of the accessions were one hundred seed weight (P100) with 24.01\%, growing season (PV) with $20.39 \%$, reproductive period (PR) with $17.16 \%$ and seed length (CS) with $14.87 \%$. The accessions were less divergent the F15 and F18 (9.18) and the most divergent F10 and F08 (1308.62). Multivariate analysis showed a low genetic similarity between cultivars and also between accessions from EMBRAPA and between them. Site accesses demonstrated significant genetic diversity. Both the cluster analysis and the canonical variables were able to separate the access according to the centers of origin.
\end{abstract}

Key words - Phaseolus vulgaris L.. Germoplasm characterization. UPGMA. Canonical variables.

\footnotetext{
* Autor para correspondência

'Recebido para publicação em 11/08/2010; aprovado em 12/04/2011

Parte da dissertação de Mestrado do primeiro autor, apresentada ao Programa de Pós-Graduação em Produção Vegetal, CCA/UFES

${ }^{2}$ Bolsista da UENF/FAPERJ, Programa de Pós-Graduação em Genética e Melhoramento de Plantas/UENF, Campos dos Goytacazes-RJ, Brasil, 28.013-602, pablodscabral@hotmail.com

${ }^{3}$ Departamento de Zootecnia/CCA-UFES, Alto Universitário, Campus Universitário, s/n, Alegre-ES, Brasil, 29.500-000, tcbsoares@yahoo.com.br ${ }^{4}$ Departamento de Produção Vegetal/CCA-UFES, Alto Universitário, Campus Universitário, s/n, Alegre-ES, Brasil, 29.500-000, andreiabpl@yahoo.com.br ${ }^{5}$ Bolsista de iniciação científica-UFES, graduando do Curso de Agronomia do CCA-UFES, Alto Universitário, Campus Universitário, s/n, Alegre-ES, Brasil, 29.500-000, diegosouzalves@hotmail.com

${ }^{6}$ Programa de Pós-Graduação em Produção Vegetal do CCA-UFES, Alto Universitário, Campus Universitário, s/n, Alegre-ES, Brasil, 29.500-000, nunesarcanjo@terra.com.br
} 


\section{Introdução}

O feijoeiro comum (Phaseolus vulgaris L.) é um alimento básico na dieta da população brasileira, sendo uma notável fonte protéica. É também um dos produtos agrícolas de maior importância sócio-econômica, devido ao grande volume de mão-de-obra que emprega durante o ciclo da cultura (VIEIRA et al., 2006).

Estudos de diversidade genética têm sido de grande importância em programas de melhoramento, por fornecerem informações sobre caracteres de identificação de genitores que possibilitem grande efeito heterótico e maior segregação em recombinantes, aumentando a probabilidade do aparecimento de genótipos superiores nas progênies (SILVA et al., 2008). Além disso, possibilita a identificação de duplicatas, reduzindo assim, gastos consideráveis na manutenção de bancos de germoplasma (RODRIGUES et al., 2002). A existência de variabilidade genética é essencial para o sucesso de programas de melhoramento de praticamente todos os caracteres de importância econômica (COSTA et al., 2004).

A grande diversidade presente no germoplasma do feijão comum utilizado na agricultura familiar no Brasil foi extremamente importante, pois auxiliou a estratégia de sobrevivência dos pequenos agricultores, visto que eles selecionavam os genótipos adaptados às condições agromorfológicas e socioeconômicas que possuíam, sendo estas condições diferentes das encontradas nos cultivos comerciais. Contudo, a variabilidade genética que era mantida pela agricultura familiar está sendo perdida em decorrência da substituição das variedades locais por cultivares comerciais (RODRIGUES et al., 2002).

O conhecimento da diversidade genética entre as cultivares locais e as melhoradas é importante para subsidiar programas de melhoramento de plantas, possibilitando explorar a variabilidade existente e já adaptada às condições climáticas de regiões específicas (FRANCO et al., 2001). Considerando que os estudos sobre estas cultivares locais ainda são escassos, o objetivo deste experimento foi estimar a diversidade genética através de caracteres agronômicos e identificar possíveis duplicatas genéticas entre os 57 acessos de feijoeiro por meio de análises multivariadas.

\section{Material e métodos}

O material genético consistiu de 57 acessos de feijoeiro comum, sendo 20 acessos fornecidos pela Empresa Brasileira de Pesquisa Agropecuária (EMBRAPA), 31 genótipos locais pertencentes à comunidade Fortaleza no município de Muqui-ES e seis cultivares comerciais: Carioca, Serrano, IAPAR 31, IAPAR 44, IAPAR 81 e Pérola (TAB. 1).

Os experimentos foram realizados na Área Experimental do Centro de Ciências Agrárias da Universidade Federal do Espírito Santo (CCA-UFES) e no Instituto Federal de Educação, Ciência e Tecnologia do Espírito Santo (IFES), Campus de Alegre, localizado no distrito de Rive, Alegre, ES, nos anos agrícolas de 2008/2009 e de 2009/2010. Dois experimentos foram conduzidos na área experimental do CCA-UFES (2008/2009 e 2009/2010) e um no IFES (2009/2010).

O delineamento utilizado foi o de blocos casualizados (DBC) com três repetições. A unidade experimental foi composta por cinco linhas de 1,2 $\mathrm{m}$ de comprimento, espaçadas $0,5 \mathrm{~m}$, com densidade de semeadura de 10 sementes por metro linear, totalizando uma área de $3 \mathrm{~m}^{2}$ por unidade experimental. Foram consideradas como bordadura, a primeira e a última linha e a primeira e última planta de cada linha por parcela. A parcela útil foi constituída por 10 plantas ao acaso. O solo foi previamente corrigido, de acordo com a necessidade de calagem (NC) e a adubação foi realizada visando atingir uma produtividade esperada em torno de 1.000 a $2.000 \mathrm{~kg} \mathrm{ha}^{-1}$, conforme recomendações de Prezotti et al., (2007).

Foram avaliados 19 caracteres agronômicos: largura em $\mathrm{cm}$ da folha primária no estádio de plântula (LFP); comprimento em $\mathrm{cm}$ da folha primária no estádio de plântula (CFP); índice de comprimento/largura da folha primária (I L/C); peso em gramas de 100 sementes (P100); largura da semente em mm (LS); espessura da semente em mm (ES); comprimento da semente em mm (CS); índice comprimento/largura da semente (IS C/L); índice espessura/largura da semente (IS E/L); produtividade em $\mathrm{kg} \mathrm{ha}^{-1}$ (PROD), altura em $\mathrm{cm}$ da planta em relação ao solo, no estádio de maturação fisiológica (AP); altura em $\mathrm{cm}$ de inserção da primeira vagem em relação ao solo, no estádio de maturação físiológica (APV); período vegetativo, número de dias após a germinação até 90\% das plantas em floração (PV); período reprodutivo, número de dias a partir de $90 \%$ das plantas em floração até a maturação colheita (PR); ciclo (soma de PR e $\mathrm{PV}$, em dias); número de semente por vagem, total de sementes dividido pelo total de vagens de cada parcela (NSV); número de vagem por planta, total de vagens dividido pelo número de plantas de cada parcela (NVP); número de semente por planta, total de sementes dividido pelo número de plantas de cada parcela (NSP); peso de semente por planta, peso total de sementes dividido pelo número de plantas de cada parcela (PSP).

Primeiramente realizou-se a análise de variância para cada experimento separadamente para a verificação de homogeneidade de variâncias dos resíduos, depois 
Tabela 1 - Identificação dos acessos utilizados, origem e peso de 100 sementes (P100)

\begin{tabular}{cccccc}
\hline Identificação & Origem & P100 (g) & Identificação & Origem & P100 (g) \\
\hline Pérola & comercial & 23,93 & F33 & local & 36,38 \\
F2 & local & 21,68 & F34 & local & 46,02 \\
F3 & local & 18,48 & F35 & local & 15,74 \\
F5 & local & 17,13 & F36 & local & 38,99 \\
F6 & local & 17,03 & F37 & local & 18,20 \\
F7 & local & 19,77 & F38 & local & 15,07 \\
F8 & local & 41,37 & E 01 & EMBRAPA & 16,68 \\
F9 & local & 36,37 & E 02 & EMBRAPA & 22,87 \\
F10 & local & 17,81 & E 03 & EMBRAPA & 19,15 \\
F11 & local & 18,50 & E 04 & EMBRAPA & 19,24 \\
F13 & local & 18,06 & Iapar 31 & comercial & 23,23 \\
F14 & local & 17,62 & E 06 & EMBRAPA & 22,27 \\
F15 & local & 14,24 & E 07 & EMBRAPA & 21,59 \\
F16 & local & 15,77 & E 08 & EMBRAPA & 20,13 \\
F17 & local & 17,76 & E 09 & EMBRAPA & 16,89 \\
F18 & local & 14,52 & E 10 & EMBRAPA & 26,39 \\
F19 & local & 18,21 & E 11 & EMBRAPA & 21,06 \\
F20 & local & 18,16 & E 12 & EMBRAPA & 22,36 \\
F21 & local & 18,84 & E 13 & EMBRAPA & 20,63 \\
F23 & local & 15,28 & E 14 & EMBRAPA & 20,21 \\
F24 & local & 17,42 & E 15 & EMBRAPA & 19,61 \\
F25 & local & 17,73 & E 16 & EMBRAPA & 21,39 \\
F26 & local & 21,97 & E 17 & EMBRAPA & 21,23 \\
Iapar 81 & comercial & 20,92 & E 18 & EMBRAPA & 20,78 \\
F28 & local & 16,97 & E 19 & EMBRAPA & 21,17 \\
Carioca & comercial & 22,10 & Iapar 44 & comercial & 19,25 \\
Serrano & comercial & 16,04 & E 21 & EMBRAPA & 28,09 \\
F31 & local & 36,20 & E 22 & EMBRAPA & 36,38 \\
F32 & local & 33,96 & & & \\
\hline & & & & & \\
\end{tabular}

de constatada, procedeu-se a análise conjunta dos experimentos até $5 \%$ de significância pelo teste $\mathrm{F}$, avaliado segundo o modelo matemático: $Y_{i j k}=\mu+G_{i}+A_{j}$ $+\mathrm{B}_{\mathrm{k}}+(\mathrm{GA})_{\mathrm{ij}}+\varepsilon_{\mathrm{ijk}}$, sendo: $\mathrm{Y}_{\mathrm{ij}}=$ valor observado para a variável referente a k-ésima repetição da combinação do i-ésimo nível do fator acesso $(\mathrm{G})$ com o j-éseimo nível do fator ambiente $(\mathrm{A}) ; \mu=$ constante (média) comum a todas as observações; $\mathrm{G}_{\mathrm{i}}=\mathrm{i}$-ésimo nível do fator $\mathrm{G} ; \mathrm{A}_{\mathrm{j}}=$ j-ésimo nível do fator $A ; B_{k}=k$-ésimo efeito de bloco (B); (GA) $)_{\mathrm{ij}}=$ efeito da interação de $\mathrm{G}_{\mathrm{i}} \operatorname{com} \mathrm{A}_{\mathrm{j}} ; \varepsilon_{\mathrm{ij}}=$ erro experimental associado a $\mathrm{Y}_{\mathrm{ijk}}$. Sendo os fatores acesso (G) e ambiente (A) considerados fixos.
A partir da análise de variância conjunta obteve-se a matriz de variância e covariância residuais e por esta a matriz de dissimilaridade entre as cultivares pela distância generalizada de Mahalanobis $\left(\mathrm{D}^{2}\right)$, a quantificação da contribuição relativa dos caracteres (S.j), obtida de acordo com Sing (1981), e os escores das variáveis canônicas (VC) utilizando o programa computacional GENES (CRUZ, 2006). Posteriormente foi realizado o agrupamento pela ligação média entre grupos (UPGMA) pelo pacote cluster do programa R (MAECHLER, 2010) e a dispersão dos escores da análise de variáveis canônicas. Para avaliar a precisão do agrupamento foi calculado o 
coeficiente de correlação cofenética (CCC), obtido com 1.000 simulações, e analisado pelo teste " $t$ " pelo software GENES (CRUZ, 2006).

\section{Resultados e discussão}

Verificaram-se diferença entre os acessos para a maioria dos caracteres avaliados, exceto para I L/C, evidenciando variabilidade entre os acessos testados (TAB. 2). Serão desconsiderados o ambiente e a interação deste com os acessos, já que o foco deste experimento é a dissimilaridade entre os acessos, sendo utilizada apenas a média dos acessos nos três ambientes para as análises multivariadas. $\mathrm{O}$ coeficiente de variação ficou entre 2,7 e $20,86 \%$, demonstrando uma boa consistência dos dados experimentais (TAB. 2).
Avaliando a correlação entre as variáveis, foi observada correlação perfeita $(1,0)$ entre as variáveis peso de semente por planta (PSP) e produtividade (PROD), o que era esperado, visto que a variável PROD é calculada através da variável PSP. Assim, segundo Cruz e Carneiro (2006), a presença de correlação alta ou perfeita, pode levar à estimativa de valores absurdos ou sem nenhuma coerência com o fenômeno biológico em estudo. Desse modo, a variável PSP foi excluída das análises, pelo fato dessa variável ser considerada de menor valor agronômico em relação à variável PROD.

$\mathrm{Na}$ Tabela 3 é apresentada a importância relativa (S.j) de cada um dos 18 caracteres agronômicos para o estudo da diversidade genética entre os 57 acessos de feijoeiro. Pode-se observar que as variáveis com as maiores contribuições relativas foram peso de 100 sementes $(24,01 \%)$, seguida por período vegetativo

Tabela 2 - Resumo da análise de variância informando os quadrados médios dos acessos, dos ambientes e da interação entre acesso e ambiente (Inter GxA), média e coeficiente de variação (CV), obtida nos 19 caracteres agronômicos

\begin{tabular}{crrrrr}
\hline \multirow{2}{*}{ Caracteres } & \multicolumn{3}{c}{ Quadrados Médios } & \multirow{2}{*}{ Média } & CV (\%) \\
\cline { 2 - 4 } & Acessos (G) & Ambientes (A) & Inter $(\mathrm{GxA})$ & & 8,05 \\
LFP & $2,03^{* *}$ & $12,66^{* *}$ & $0,240^{*}$ & 5,56 \\
CFP & $1,29^{* *}$ & $24,59^{* *}$ & $0,350^{\text {ns }}$ & 5,75 & 9,57 \\
I L/C & $0,00^{\text {ns }}$ & $4,08^{* *}$ & $0,016^{* *}$ & 0,97 & 6,64 \\
AP & $3544,26^{* *}$ & $24241,89^{* *}$ & $167,770^{\text {ns }}$ & 60,16 & 20,86 \\
APV & $152,30^{* *}$ & $256,46^{* *}$ & $6,290^{* *}$ & 15,37 & 13,03 \\
PV & $227,90^{* *}$ & $81,69^{* *}$ & $1,330^{\text {ns }}$ & 36,22 & 6,08 \\
PR & $99,45^{* *}$ & $104,41^{* *}$ & $0,590^{*}$ & 37,31 & 4,43 \\
Ciclo & $224,09^{* *}$ & $307,20^{* *}$ & $2,100^{* *}$ & 73,53 & 5,59 \\
NSV & $3,23^{* *}$ & $0,45^{* *}$ & $0,050^{\text {ns }}$ & 4,12 & 8,23 \\
NVP & $41,62^{* *}$ & $57,27^{* *}$ & $1,100^{\text {ns }}$ & 8,16 & 15,00 \\
NSP & $989,47^{* *}$ & $1473,60^{* *}$ & $22,110^{\text {ns }}$ & 33,70 & 13,39 \\
PSP & $37,24^{* *}$ & $296,21^{* *}$ & $1,880^{* *}$ & 6,98 & 14,33 \\
P100 & $430,92^{* *}$ & $876,04^{* *}$ & $4,800^{* *}$ & 21,66 & 4,55 \\
PROD & $1489712,00^{* *}$ & $11848704,00^{* *}$ & $75263,000^{* *}$ & 1397,99 & 14,33 \\
CS & $0,19^{* *}$ & $0,03^{* *}$ & $0,002^{* *}$ & 1,01 & 2,70 \\
LS & $0,02^{* *}$ & $0,12^{* *}$ & $0,001^{* *}$ & 0,60 & 2,90 \\
ES & $0,02^{* *}$ & $0,13^{* *}$ & $0,001^{* *}$ & 0,45 & 3,74 \\
IS C/L & $0,29 * *$ & $0,72^{* *}$ & $0,008^{* *}$ & 1,68 & 2,85 \\
IS E/L & $0,02^{* *}$ & $0,02^{* *}$ & $0,001^{* *}$ & 0,74 & 3,52 \\
\hline
\end{tabular}

${ }^{1}$ LFP: largura da folha primaria; CFP: comprimento da folha primária; I L/C: índice entre largura e comprimento da folha primária; AP: altura da planta; APV: altura da primeira vagem; PV: período vegetativo; PR: período reprodutivo; Ciclo: ciclo; NSV: número de semente por vagem; NVP: número de vagem por planta; NSP: número de semente por planta; PSP: peso de semente por planta; P100: peso de 100 grãos; PROD: produtividade; CS: comprimento da semente; LS: largura da semente; ES: espessura da semente; IS C/L: índice entre comprimento e largura da semente; IS E/L índice entre espessura e largura da semente. ${ }^{*} \mathrm{e}^{* *}$ : significativo a 5 e $1 \%$, respectivamente, $\mathrm{e}^{\text {ns. }}$ não significativo pelo teste $\mathrm{F}$ 
(20,39\%), período reprodutivo $(17,16 \%)$ e comprimento de semente $(14,87 \%)$. Resultados semelhantes foram demonstrados por Benin et al. (2002) e Coelho et al. (2007). Elias et al. (2007) observaram que a variável P100 foi a de maior contribuição na separação dos acessos de feijoeiro.

Tabela 3 - Importância relativa (S.j) de caracteres agronômicos para o estudo da diversidade genética entre 57 acessos de feijoeiro

\begin{tabular}{ccc}
\hline Variáveis & S.j & S.j (\%) \\
\hline P100 & 205542,90 & 24,010 \\
PV & 174568,70 & 20,392 \\
PR & 146914,30 & 17,162 \\
CS & 127361,30 & 14,877 \\
Ciclo & 87333,74 & 10,202 \\
ES & 31689,20 & 3,702 \\
LS & 21898,32 & 2,558 \\
APV & 14867,23 & 1,737 \\
PROD & 10924,11 & 1,276 \\
IS C/L & 6659,44 & 0,778 \\
NSV & 6383,49 & 0,746 \\
NSP & 5343,30 & 0,624 \\
AP & 4980,44 & 0,582 \\
NVP & 3352,77 & 0,392 \\
LFP & 3166,55 & 0,369 \\
IS E/L & 2336,83 & 0,273 \\
CFP & 1768,32 & 0,207 \\
I L/C & 973,45 & 0,114 \\
\hline
\end{tabular}

1P100: peso de cem grãos; PV: período vegetativo; PR: período reprodutivo; CS: comprimento da semente; Ciclo: ciclo; ES: espessura da semente; LS: largura da semente; APV: altura da primeira vagem; PROD: produtividade; IS C/L: índice entre comprimento e largura da semente; NSV: número de semente por vagem; NSP: número de semente por planta; AP: altura da planta; NVP: número de vagem por planta; LFP: largura da folha primária; IS E/L índice entre espessura e largura da semente; CFP: comprimento da folha primaria; I L/C: índice entre largura e comprimento da folha primária

A produtividade, apesar de ser um importante caráter comercial, teve baixo poder discriminante entre os acessos, o que pode ser explicado pela baixa heterogeneidade produtiva observada entre os acessos, como também foi observado por Coelho et al. (2007).

As variáveis que menos contribuíram para diferenciar os acessos foram: I L/C (0,1137\%), CFP
$(0,2066 \%)$, IS E/L $(0,273 \%)$, LFP $(0,3699 \%)$ e NVP $(0,3916 \%)$. Rodrigues et al. (2002) concluíram que as variáveis de menor importância para diferenciar as cultivares locais e melhoradas de feijoeiro foram o índice comprimento e largura da folha, largura e comprimento da folha primária, grau de achatamento da semente e forma da semente. Cruz e Carneiro (2006) relataram que as características de menor importância para estimar a diversidade entre indivíduos são as que apresentam menor variabilidade ou que estão representadas por outras.

O coeficiente de correlação cofenética (CCC) é uma medida de concordância entre os valores originais de dissimilaridade e os representados pelo dendrograma, quanto maior o CCC menor será a distorção do agrupamento (CRUZ; CARNEIRO, 2006). O CCC obtido foi de 0,91 e significativo a $1 \%$ de probabilidade pelo teste " $t$ ", o que representa um alto ajuste entre a matriz cofenética e a matriz de dissimilaridade com base na distância generalizada de Mahalanobis, demonstrando alta confiabilidade do agrupamento. Bertan et al. (2006) relataram a alta precisão do agrupamento UPGMA pela dissimilaridade obtida pela distância generalizada de Mahalanobis em relação a outras medidas de dissimilaridade.

A partir do corte no dendrograma, em aproximadamente $50 \%$, foi observada a formação de quatro grupos (FIG. 1). A menor dissimilaridade foi entre os acessos F15 e F18 $(9,18)$ e a maior entre F10 e F08 $(1308,62)$. Não foram observados acessos geneticamente idênticos, mas é notória a similaridade genética entre os pares de acessos F15 e F18, entre F14 e E09 e entre E13 e E21.

Segundo Kwak e Gepts (2009) o feijão foi domesticado nas Américas em dois centros de origem principais, um que compreende a região do México e a America Central, sendo os genótipos provenientes deste centro denominados de Mesoamericanos, e o outro na região do Peru, denominados de Andinos. Coelho et al. (2007) relataram que os genótipos de feijoeiro com peso de 100 sementes inferior a 25,00 g pertencem possivelmente ao centro Mesoamericano e aqueles com peso superior a 33,00 g, ao Andino. Nesse sentido, os grupos G1 (F36, F08 e F34) e G4 (E22, F09, F33, F31 e F32) reuniram os acessos com os maiores valores de P100, todos acima de 33 g (TAB. 1). Já nos grupos G2 (F10) e G3 (F16, F17, E07, Pérola, E10, E19, F28, F37, E03, E13, E21, E11, E14, F14, E09, E08, Iapar 44, F15, F18, F23, F38, Carioca, F20, Iapar 81, E12, E02, F02, F07, F25, E01, E06, E16, F26, Iapar 31, E17, F19, Serrano, F35, F13, E18, F06, F21, E11, E15, F05, F24, F03, E04) encontram-se os acessos com os menores pesos de cem sementes (TAB. 1). Desta forma, o agrupamento foi capaz de separar os acessos de 


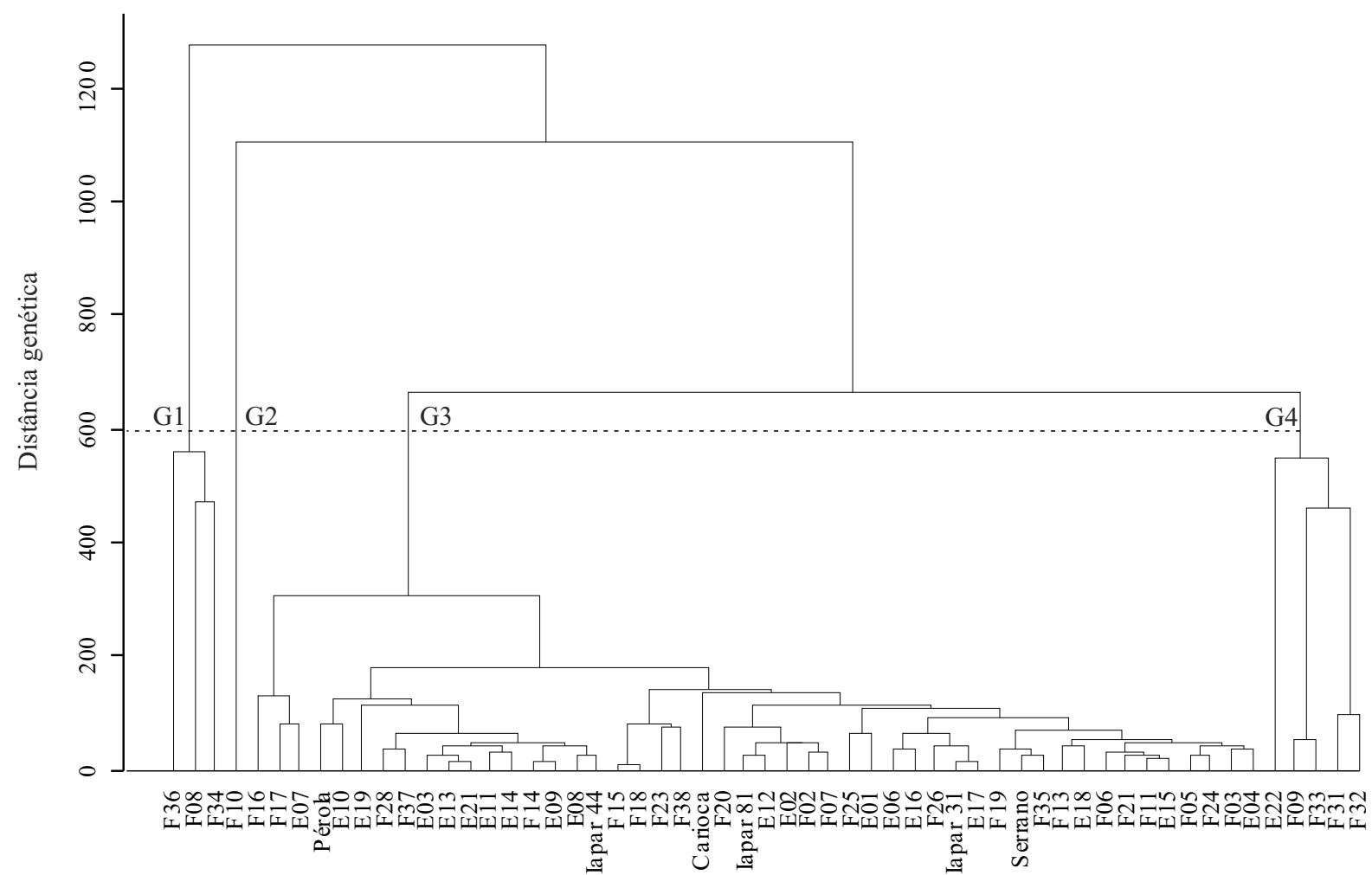

Figura 1 - Dendrograma obtido por meio de dados quantitativos com a distância generalizada de Mahalanobis e pelo método de agrupamento UPGMA, dos 57 acessos de feijoeiro. Linha pontilhada: corte no dendrograma em aproximadamente $50 \%$ da máxima distância; G 1 a G 4 representam os 4 grupos formados

acordo com o centro de origem. Resultados semelhantes foram relatados por Coelho et al. (2007) e Barelli et al. (2009). Cabral et al. (2011) avaliando a diversidade de genótipos de feijoeiro através de marcadores moleculares microssatelites (SSR), observaram o agrupamento de acordo com os centros de origem.

Os acessos E10 e E21 não apresentaram P100 abaixo de $25 \mathrm{~g}$ e estão agrupados com os acessos de origem Mesoamericanos. Assim, segundo AlzateMarin et al. (2003) alguns genótipos, apesar de terem sementes grandes e pesadas, apresentam baixa porcentagem de genes andinos.

No grupo G3, estão todas as cultivares comerciais (Serrano, Iapar 81, Iapar 31, Carioca, Pérola e Iapar 44) e também a grande maioria das cultivares provenientes da EMBRAPA, à exceção do genótipo E22, verificando-se uma pequena variabilidade genética entre as cultivares comerciais, entre os acessos da EMBRAPA e entre ambos (EMBRAPA e Comerciais). Rodrigues et al. (2002) trabalhando com diversidade genética de cultivares de feijoeiro no Rio Grande do Sul, por meio de descritores morfoagronômicos, relataram que os genótipos comerciais avaliados apresentam alto grau de similaridade entre si. Cabral et al. (2010) avaliando a diversidade de cultivares locais do sul do Espírito Santo, da EMBRAPA e comerciais, através da técnica Ward MLM, observaram que os genótipos locais tinham maior variabilidade genética do que as cultivares provenientes da EMBRAPA e das cultivares comerciais.

A distribuição dos acessos no dendrograma demonstra que os acessos provenientes da EMBRAPA apresentaram uma baixa dissimilaridade, sendo o acesso E22 o mais divergente entre eles. Já os acessos locais (comunidade Fortaleza) apresentaram ampla variabilidade genética. Bonett et al. (2006) também concluíram que as cultivares locais utilizadas pelos agricultores no Paraná têm ampla variabilidade genética.

As três primeiras variáveis explicaram $82,16 \%$ da variação total, sendo $44,90 \%$ para a primeira, $26,71 \%$ para a segunda e $10,55 \%$ para a terceira (FIG. 2). Krause et al. (2009) observaram que as duas primeiras variáveis 


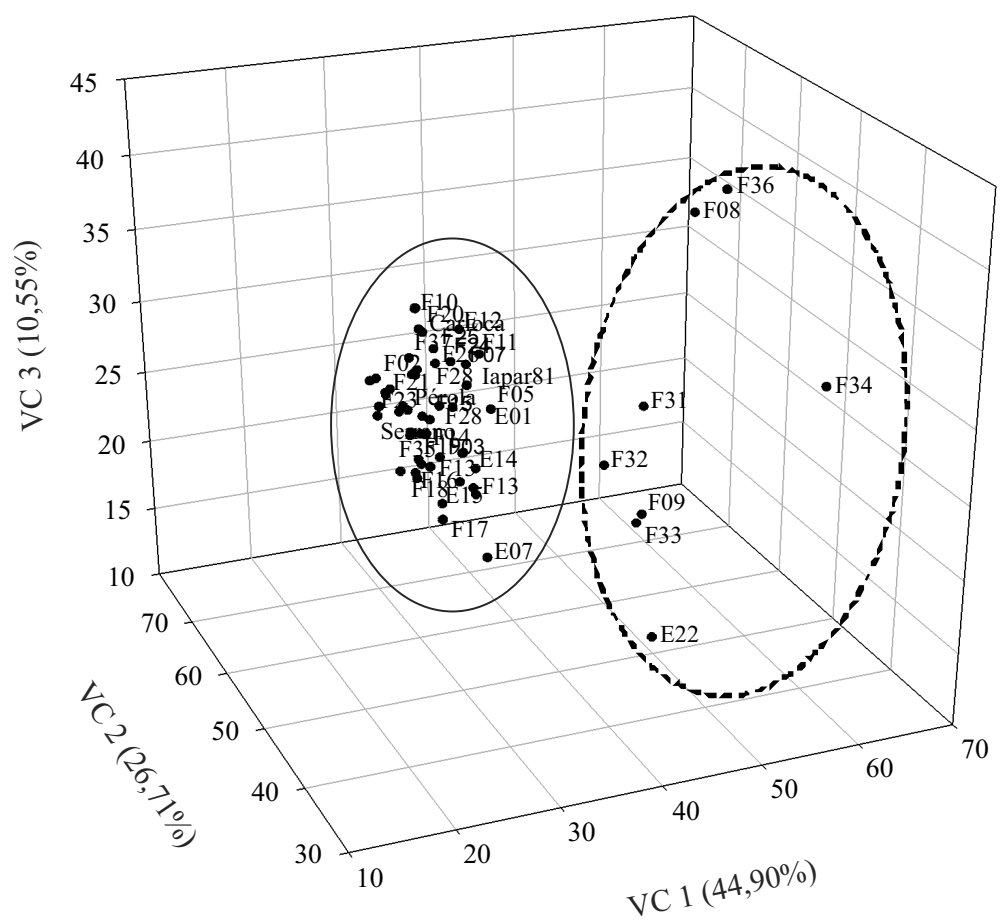

Figura 2 - Dispersão gráfica dos 57 acessos de feijão em relação às duas primeiras variáveis canônicas, estabelecidas pela combinação linear de dezoito características agronômicas. As linhas delimitam os grupos formados: ( $\_$) corresponde ao grupo G'1 e (----) corresponde ao grupo G'2

canônicas explicaram aproximadamente $80 \%$ da variação total. Machado et al. (2002) avaliando a diversidade genética entre genótipos de feijão através de variáveis canônicas observaram que as três primeiras variáveis explicaram 99\% da variação total. Cruz e Carneiro (2006) ressaltam que a análise por variáveis canônicas só deve ser utilizada quando, em duas ou três variáveis canônicas, é explicado mais de $80 \%$ da variação total.

De acordo com os dois grupos formados, G'1 abriga todos os acessos considerados de origem Mesoamericana e no G'2 estão presentes os acessos considerados de origem Andina. Embora tenha sido observado um número de grupos diferentes quando foramutilizadas as análises de agrupamento e variáveis canônicas, ainda foi possível separar os acessos pelo centro de origem em ambas as análises. Teixeira et al. (2004) e Krause et al. (2009) observaram concordância entre o número de grupos formados pela análise de agrupamento e pela análise de variáveis canônicas.

A dispersão gráfica das variáveis canônicas demonstrou com maior clareza a alta similaridade genética entre as cultivares comerciais, entre os acessos provenientes da EMBRAPA e entre ambos e também a maior diversidade genética dos acessos locais distribuídas nos dois grupos formados.

\section{Conclusões}

1. Os acessos locais apresentaram divergência significativa, o que não foi observado entre os acessos da Embrapa e nem entre as cultivares comerciais;

2. Não foram observadas duplicatas genéticas entre os acessos;

3. As variáveis com maior contribuição para a separação dos acessos foram peso de 100 sementes, período vegetativo, período reprodutivo e comprimento de semente, respectivamente;

4. Tanto as análises de agrupamento quanto a de variáveis canônicas foram parcialmente concordantes nos agrupamentos dos acessos.

\section{Agradecimentos}

Os autores agradecem à Fundação de Amparo à Pesquisa do Espírito Santo (FAPES) e a Coordenação de Aperfeiçoamento de Pessoal de Nível Superior (CAPES), pelo financiamento do projeto e pela concessão da bolsa de mestrado ao primeiro autor, respectivamente. 


\section{Referências}

ALZATE-MARIN, A. L. et al. Genetic Variability and Pedigree Analysis of Brazilian Common Bean Elite Genotypes. Scientia Agricola, v. 60, n. 02, p. 283-290, 2003.

BARELLI, M. A. A. et al. Genetic divergence in common bean landrace cultivars from Mato Grosso do Sul State. Semina: Ciências Agrárias, v. 30, p. 1061-1072, 2009.

BENIN, G. et al. Identificação da dissimilaridade genética entre genótipos de feijoeiro comum (Phaseolus vulgaris L.) do grupo preto. Revista Brasileira Agrociência, v. 08, n. 03, p. 179-184, 2002.

BERTAN, I. et al. Comparação de métodos de agrupamento na representação da distância morfológica entre genótipos de trigo. Revista Brasileira de Agrociência, v. 12, n. 03, p. 279-286, 2006.

BONETT, L. P. et al. Divergência genética em germoplasma de feijoeiro comum coletado no estado do Paraná, Brasil. Semina: Ciências Agrárias, v. 27, n. 04, p. 547-560. 2006.

CABRAL, P. D. S. et al. Genetic diversity in local and commercial dry bean (Phaseolus vulgaris) accessions based on microsatellite markers. Genetics and Molecular Research, v. 10, n. 01, p. 140-149, 2011.

CABRAL, P. D. S. et al. Quantification of the diversity among common bean accessions using Ward MLM strategy. Pesquisa Agropecuária Brasileira, v.45, n.10, p.1124-1132, 2010

COELHO, C. M. M. et al. Diversidade genética em acessos de feijão (Phaseolus vulgaris L.). Ciência Rural, v. 37, n. 05, p. 1241-1247, 2007.

COSTA, M. M. et al. Ganho genético por diferentes critérios de seleção em populações segregantes de soja. Pesquisa Agropecuária Brasileira, v. 39, n. 11, p. 1095-1102, 2004.

CRUZ, C. D.; CARNEIRO, P. C. S. Modelos biométricos aplicados ao melhoramento genético. 2. ed. Viçosa: UFV,v2, p. 585, 2006.

CRUZ, C. D. Programa Genes: versão Windows; aplicativo computacional em genética e estatística. Viçosa: Imprensa Universitária, 648p. 2006.
ELIAS, H. T. et al. Variabilidade genética em germoplasma tradicional de feijão-preto em Santa Catarina. Pesquisa Agropecuária Brasileira, v. 42, n. 10, p. 1443-1449, 2007.

FRANCO, M. C. et al. Caracterização da diversidade genética em feijão por meio de marcador RAPD. Pesquisa Agropecuária Brasileira, v. 36, p. 381-385, 2001.

KRAUSE, W. et al. Genetic divergence in snap bean based on agronomic traits and resistance to bacterial wilt. Crop Breeding and Applied Biotechnology, v. 09, p. 246-252, 2009.

KWAK, M.; GEPTS, P. Structure of genetic diversity in the two major gene pools of common bean (Phaseolus vulgaris L., Fabaceae). Theoretical and Applied Genetics, v. 118, p. 979-992, 2009.

MACHADO, C. de F. et al. Divergência genética entre genótipos de feijoeiro a partir de técnicas multivariadas. Ciência Rural, v. 32, n. 02, p. 251-258, 2002.

MAECHLER, M. Cluster: Cluster Analysis Extended Rousseeuw. 2010. Disponível em: http://brieger.esalq.usp.br/ CRAN/. Acesso em: 25 mar. 2010.

PREZOTTI, L. C. et al. Manual de Recomendação de Calagem e Adubação para o Estado do Espírito Santo - $5^{\text {a }}$ aproximação. SEEA/INCAPER/CREDAGRO, Vitória, ES; 305p. 2007.

RODRIGUES, L. S. et al. Divergência genética entre cultivares locais e cultivares melhoradas de feijão. Pesquisa Agropecuária Brasileira, v. 37, n. 09, p. 1275-1284, 2002.

SILVA, G. O. da, et al. Importância de caracteres na dissimilaridade de progênies de batata em gerações iniciais de seleção. Bragantia, v. 67, n. 01, p. 141-144, 2008.

SINGH, D. The relative importance of characters affecting genetic divergence. The Indian Journal of Genetics \& Plant Breeding, New Delhi, v. 41, p.237-245, 1981.

VIEIRA, C. Cultura do feijão. 2. ed. Viçosa, MG: UFV, 146 p, 2006.

TEIXEIRA, A. B. et al. Genetic divergence in snap-bean (Phaseolus vulgaris L.) evaluated by different methodologies. Crop Breeding and Applied Biotechnology, v. 04, p. 5762, 2004. 